\title{
Selective laser sintering of polyamide 12/flame retardant compositions
}

\author{
Marcos Batistella ${ }^{a, *}$, Arnaud Regazzi ${ }^{b}$, Monica Francesca Pucci ${ }^{b}$, José-Marie Lopez-Cuesta $^{a}$, \\ Ouassila Kadri ${ }^{c}$, David Bordeaux ${ }^{c}$, Florence Ayme ${ }^{c}$
}

a Polymers Composites and Hybrids (PCH), IMT Mines Ales, 6, Avenue des Clavières, 30319 Ales, France

${ }^{\mathrm{b}}$ LMGC, IMT Mines Ales, Univ Montpellier, CNRS, Ales, France

c SD Tech, Ales, France

\section{A R T I C L E I N F O}

\section{Keywords:}

Polyamide 12

Selective laser sintering

flame retardants

\begin{abstract}
A B S T R A C T
In this work, various flame retardants (FR) and clays were added to polyamide 12 (PA12). The processability by Selective Laser Sintering (SLS), thermal behaviour and flame retardancy of these compounds were evaluated. The observations show an important impact on powder flowability of some formulations containing melamine cyanurate and melamine polyphosphate leading to difficulties during SLS process. The incorporation of FRs also leads to changes in melting and crystallization temperatures of polyamide as a function of the FR type. Furthermore, in order to evaluate the influence of the process on thermal properties of samples, a comparison between thermocompression (TC) and SLS techniques was performed for the formulations containing the flame retardants alone. The addition of flame retardants impacts the porosity of the SLS samples as a function of the FR type. For the additives which are able to melt during SLS process, a lower porosity was observed. Samples made by TC containing 30 wt\% of ammonium polyphosphate, zinc diethylphosphinate and a pentaerythritol ester of methane phosphonic acid showed a better thermal stability and flame retardancy compared to the ones made by SLS, probably due to the porosity of the SLS samples and some degradation of the flame retardant by the laser beam. For the formulation containing only zinc borate, no difference was observed between TC and SLS. In order to evaluate possibly synergistic effects between flame retardants, binary and ternary formulations were prepared by SLS. On the whole, these formulations led to an improvement of flame retardancy compared to neat PA12. Moreover, XRD results showed the formation of borophosphates for binary and ternary formulations, indicating interactions between flame retardants. EDX results showed that at least $95 \%$ of the phosphorus remained in the residue for the formulations containing zinc borate, thus corroborating the results obtained by XRD. The partial substitution of zinc borate by kaolinite led to a further improvement of flame retardancy at the expense of a porosity increase in the samples.
\end{abstract}

\section{Introduction}

Among the different additive manufacturing techniques available at industrial level, Selective Laser Sintering (SLS) allows very complex shapes to be processed but requires specific properties for the powders used to build the final objects. These characteristics make this technique suitable for the production of prototypes or service parts for various applications, especially aerospace and defence industries. However, these industries have some of the toughest performance standards and need the production of parts with improved properties as flame retardancy [1-3]. The SLS process is based on the selective fusion of polymer powders layer by layer using generally a $\mathrm{CO} 2$ laser. The process is performed in three

\footnotetext{
* Corresponding author.

E-mail address: marcos.batistella@mines-ales.fr (M. Batistella).
}

main steps: powder spreading, energy input and material consolidation. The material, which is mainly a semi-crystalline polymer, is preheated at a temperature between melting and crystallization points. Afterwards, the powder is selectively melted by the laser, while surrounding powder particles remain solid in the building chamber. After sintering, the building chamber is lowered by a height corresponding to the powder layer thickness and the process is repeated with the spreading of the following layer until the complete building of the object (Fig. 1). The meaning of sintering corresponds here to the coexistence of the initial powder with the melted polymer during the building of the object since the process temperature has to be selected between the melting and crystallization points of the polymer [4]. This hysteresis between these temperatures is usually called processing window and allows the polymer particles to coalesce and a homogeneous layer to be built. The coalescence is governed by the viscosity and surface tension 


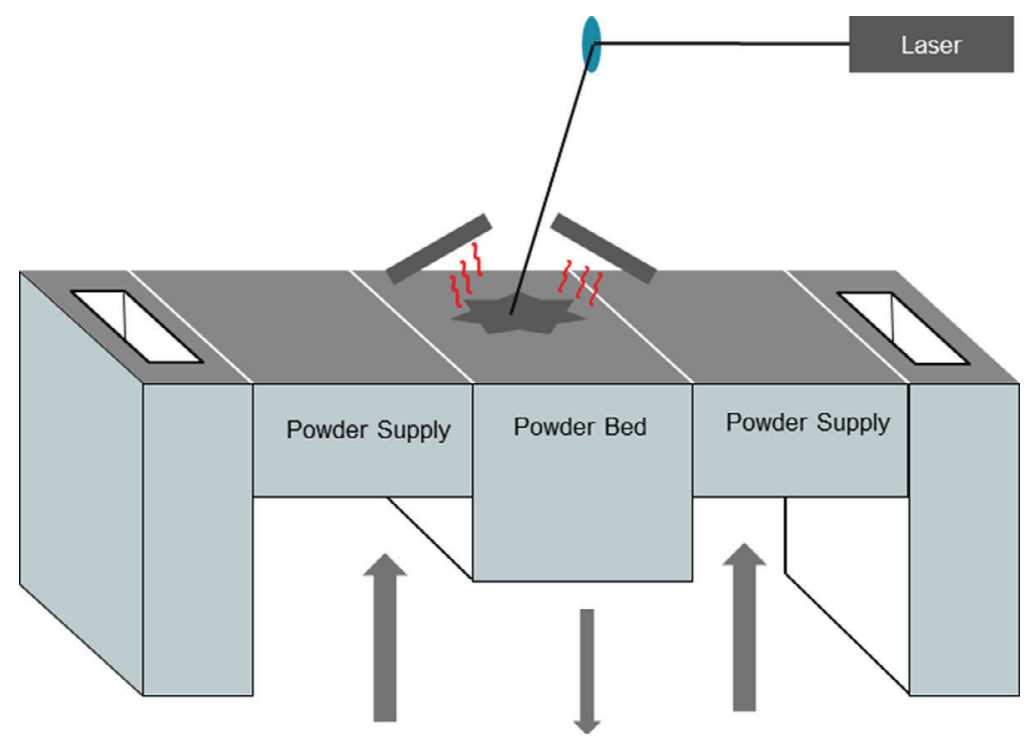

Fig. 1. Schematic representation of the SLS process.

of the melt and there is no pressure applied, conversely to conventional polymer processing techniques $[5,6]$.

Despite SLS is able to process any polymer able to fuse when heat is applied [7], mainly a limited range of semi-crystalline polymers have been used until now: polyamide 11 and 12, polyaryletherketones (PAEK), and more recently polyurethanes (PU) and polybutylene terephthalate (PBT) [8,9]. In fact, polyamide based materials represent more than $90 \%$ of the SLS production [3]. Polymer blends, composite materials and incorporation of additives are expected to increase the potential of SLS and the range of functional properties.

Most research articles deal with the improvement of mechanical or tribological properties of PA11 and PA12 through the addition of reinforcing micro- or nanofillers such as glass beads [10], molybdenum sulfur [11], carbon nanotubes [12], fibres [13,14] or nanofibers [15], silica [16], alumina [17] silicon carbide [18] or with the increase of electrical conductivity using carbon black particles [19] or for applications requiring a metallic appearance [20]. To our knowledge, even if commercial flame-retardant compositions are available, no research work has been published about flame retarded PA11 or 12 based on non-halogenated additives combined with polymer powders as powder mixtures or powders containing both the polymer and the additives.

In various studies corresponding to the incorporation of flameretardant systems through melt blending, mainly using twin-screw extruders or internal mixers, it has been shown that the combination of phosphorous or nitrogenous compounds with ultrafine mineral particles or nanoparticles could lead to synergistic effects regarding fire performance, specifically in polyamides. Synergistic effects on flame retardancy between ultrafine kaolinite and aluminium phosphinate were highlighted in PA6 [21]. Organomodified montmorillonites were also successfully associated with aluminum salt of diisobutylphosphinic acid (ABPA) in PA6 [22].

On the whole, few research works were performed on flame retarded PA11 or PA12 in comparison with PA6 or PA66. Levchik et al. investigated initially the interest of the incorporation of ammonium polyphosphate in PA11 and 12 [23]. Liu et al. incorporated an intumescent system containing APP and pentaerythritol in PA12 [24]. Lao et al. $[25,26]$ have associated successfully carbon nanofibers or nanoclays with an intumescent system based on aluminium diethylphosphinate. Gentiluomo et al. [27] have shown the interest of the incorporation of POSS and CNT to improve the fire retardancy of PA12. Moreover, the interest of high aspect ratio talcs [28] and kaolinites [29] was highlighted in order to reduce the heat release rate of filled polymers in cone calorimeter tests. More recently, our research group tested nanoboehmites in PA11 and a reduction in heat release rate was observed and ascribed to a barrier effect, while endothermic water release seemed to play a minor role [30].

Owing to the specific character of the SLS process, it has to be considered that the nature of flame-retardant systems that can be used, can be different from those devoted to melt blending techniques. At first, possible hydrolytic degradation of polymers caused by additives releasing water vapour occurring during extrusion can be avoided since the melted fraction of polymer is limited in SLS and the sintering process occurs in a limited time. Conversely, poor flowing ability for some FR additives as powders could hinder the fabrication of SLS parts. Moreover, it is required that FR additives do not undergo thermal degradation when submitted to the laser beam during the sintering process. However, a controlled melting of FR additives could be beneficial since it could help to the global sintering process and also could allow the final porosity of the material to be reduced.

The objective of the present work is to investigate the processability through SLS technology and the fire performance of different compositions based on powder mixtures of PA12 and flameretardant systems, containing usual flame-retardant additives alone or a combination of these ones with submicronic particles. Comparisons were made with similar compositions processed through thermo-compression (TC compositions). Various FR additives based on nitrogenous and phosphorous molecules were selected and tested alone or blended, according to the research of synergistic effects due to complementary modes of action and the possibility to facilitate the sintering process while maintaining a good processing window. These FR additives were completed by zinc borate which is able to create vitreous protective structures and by ultrafine mineral fillers in order to promote barrier effects.

\section{Materials and methods}

PA12 (PA2200) powder with a median diameter $\left(D_{50}\right)$ of $58 \mu \mathrm{m}$ was supplied by EOS.

A panel of six flame retardants was tested:

- melamine cyanurate: Melapur MC50 from BASF $\left(D_{50}=4 \mu \mathrm{m}\right)$,

- melamine polyphosphate: Melapur M200 from BASF ( $\left.D_{50} 6 \mu \mathrm{m}\right)$, 
Table 1

Composition of flame retarded PA12 formulations.

\begin{tabular}{llllllllll}
\hline Sample & PA2200 & $\begin{array}{l}\text { Melapur } \\
\text { MC50 }\end{array}$ & $\begin{array}{l}\text { Melapur } \\
\text { M200 }\end{array}$ & $\begin{array}{l}\text { Exolit } \\
\text { AP422 }\end{array}$ & $\begin{array}{l}\text { Exolit } \\
\text { OP950 }\end{array}$ & $\begin{array}{l}\text { Firebrake } \\
\text { ZB }\end{array}$ & $\begin{array}{l}\text { Aflammit } \\
\text { PCO900 }\end{array}$ & Kaolin & Talc \\
\hline PA & 100 & 0 & 0 & 0 & 0 & 0 & 0 & 0 & 0 \\
MC30 & 70 & 30 & 0 & 0 & 0 & 0 & 0 & 0 & 0 \\
MP30 & 70 & 0 & 30 & 0 & 0 & 0 & 0 & 0 & 0 \\
AP30 & 70 & 0 & 0 & 30 & 0 & 0 & 0 & 0 & 0 \\
OP30 & 70 & 0 & 0 & 0 & 30 & 0 & 0 & 0 & 0 \\
ZB30 & 70 & 0 & 0 & 0 & 0 & 30 & 0 & 0 & 0 \\
AF30 & 70 & 0 & 0 & 0 & 0 & 0 & 30 & 0 & 0 \\
AP15OP15 & 70 & 0 & 0 & 15 & 15 & 0 & 0 & 0 & 0 \\
AP15ZB15 & 70 & 0 & 0 & 15 & 0 & 15 & 0 & 0 & 0 \\
AP10OP10ZB10 & 70 & 0 & 0 & 10 & 10 & 10 & 0 & 0 & 0 \\
AP10AF10ZB10 & 70 & 0 & 0 & 10 & 0 & 10 & 10 & 0 & 0 \\
AP10AF10ZB5KA5 & 70 & 0 & 0 & 10 & 0 & 5 & 10 & 5 & 0 \\
AP10AF10ZB5TA5 & 70 & 0 & 0 & 10 & 0 & 5 & 10 & 0 & 5 \\
\hline
\end{tabular}

- ammonium polyphosphate: Exolit AP 422 from Clariant $\left(D_{50}=17 \mu \mathrm{m}\right)$,

- zinc diethylphosphinate: Exolit OP 950 from Clariant $\left(\mathrm{D}_{50}=10 \mu \mathrm{m}\right)$

- zinc borate $2 \mathrm{ZnO} \cdot 3 \mathrm{~B}_{2} \mathrm{O}_{3} \cdot 3.5 \mathrm{H}_{2} \mathrm{O}$ : Firebrake $\mathrm{ZB}$ from Rio Tinto Minerals $\left(D_{50}=9 \mu \mathrm{m}\right)$,

- pentaerythritol ester of methane phosphonic acid: Aflammit PCO900 from Thor $\left(D_{50}=20 \mu \mathrm{m}\right)$ a water soluble flame retardant.

In order to investigate possible synergistic effects due to barrier phenomena, two kinds of ultrafine lamellar fillers were tested:

- High Aspect Ratio Talc (HAR T84 from Imerys, $\mathrm{D}_{50}=5 \mu \mathrm{m}$, $\mathrm{S}_{\mathrm{BET}}=20 \mathrm{~m}^{2} / \mathrm{g}$ ),

- Ultrafine kaolinite (Paralux from Imerys, $\mathrm{D}_{50}=0.8 \mu \mathrm{m}$, $\left.\mathrm{S}_{\mathrm{BET}}=19 \mathrm{~m}^{2} / \mathrm{g}\right)$

Table 1 summarizes the compositions processed by SLS and TC. It should be noted that some mixed compositions could not be processed, particularly blends containing Aflammit (see infra). The following abbreviations for each additive were used followed by their content in weight: AP - Ammonium Polyphosphate; OP - Zinc Diethylphosphinate; AF - Aflammit PCO900; ZB - Zinc Borate; KA - Kaolin; TA - Talc. For example, a formulation named AP10OP10ZB10 contains 10\%wt. of ammonium polyphosphate, $10 \%$ wt. of zinc diethylphosphinate and $10 \%$ wt. of zinc borate.

The different powders were physically blended using a Mixing Station P1 from EOS.

Test specimens (sheets of $70 \times 70 \times 4 \mathrm{~mm}^{3}$ for cone calorimeter tests and $80 \times 12.9 \times 3.2 \mathrm{~mm}^{3}$ for UL94 were produced with a SLS machine (SnowWhite from Sharebot). It should be observed that the dimensions for specimens for UL94 tests are not standard due to a limitation in the size of the samples that can be made using SnowWhite equipment. Sheets of $70 \times 70 \times 4 \mathrm{~mm}^{3}$ were also made by thermocompression press (Darragon). Various parameters of SLS processing (powder temperature, laser power and laser scan speed) were tested in order to allow a satisfactory building of the specimens to be achieved. Hatching distance and layer thickness were kept constant for all tests $(0.1 \mathrm{~mm})$. Thermocompression (TC) was performed at $210^{\circ} \mathrm{C}$ and 25 bar for $3 \mathrm{~min}$.

A cone calorimeter from Fire Testing Technology was used with an irradiance of $35 \mathrm{~kW} / \mathrm{m}^{2}$ to test SLS and TC plates. The following parameters were determined: time to ignition (TTI), peak of rate release rate (pHRR), mass loss rate, total heat released (THR) and maximum of average rate of heat emission (MARHE) as a function of time. The flammability of the materials was also determined by UL94 Vertical test using sample dimensions of $80 \times 12.9 \times 3.2 \mathrm{~mm}^{3}$.

Thermal stability of individual components and FR compositions were investigated using thermogravimetric analysis (SETSYS
Evolution from Setaram) under nitrogen flow (100 mL/min) from 50 to $750^{\circ} \mathrm{C}$ at $10^{\circ} \mathrm{C} / \mathrm{min}$. The determination of SLS processing windows regarding the incorporation of the different FR additives was carried out using differential scanning calorimetry (DSC Pyris Diamond from Perkin-Elmer). A temperature ramp of $10^{\circ} \mathrm{C} / \mathrm{min}$ was applied to investigate fusion and crystallization processes defining the SLS processing window. All tests were carried out on the powder mixtures and first heating and cooling cycles were analysed.

The microstructure of initial specimens and the aspect of cone calorimeter residues were analysed using an environmental scanning electron microscope (Quanta 200 FEG from FEI Company) equipped with an energy-dispersive X-ray spectroscope (INCA Energy 300 from Oxford Instruments) for the composition determination.

In order to evaluate sample porosity, the density of the powder blends and parts were determined using a helium pycnometer (AccuPyc 1330 from Micromeritics). The internal porosity $\phi$ was then calculated according to Eq. (1):

$\phi(\%)=\frac{\rho_{p}}{\rho_{s}} \times 100$

where $\rho_{p}$ and $\rho_{s}$ are the density of the powder blend and the printed part respectively.

The characterization of mineral fillers and the possible evolution of crystalline structures occurring from thermal decomposition of flame retarded materials was carried out using X-ray diffraction (D8 Advance diffractometer from Bruker AXS with $\mathrm{CuK} \alpha$ radiation and a Lynxeye detector) in the $10-60^{\circ} 2 \theta$ range with a steep size of $0.007^{\circ}$.

\section{Results and discussion}

\subsection{Influence of additives on sintering window}

SLS technology needs also materials with a relevant processing window (i.e. the range between onset melt and crystallization temperatures). As both melted and solid polymer coexist during the process, a difference of about $20^{\circ} \mathrm{C}$ is generally needed to achieve cohesive parts. The use of additives may modify this sintering window and they have to be selected regarding their ability to maintain this range in comparison with the pure polymer.

Fig. 2 and Table 2 present the influence of various flame retardants on the processing window for formulations containing 30 wt\%. It can be noticed that the largest ranges are obtained with $\mathrm{OP}$ and $\mathrm{AF}$, whereas MC and MP lead to the narrowest ones. SLS polyamide 12 is produced by dissolving polyamide 12 at higher pressure in ethanol followed by slow crystallisation which forms crystals with a melting point of about $190^{\circ} \mathrm{C}$. 

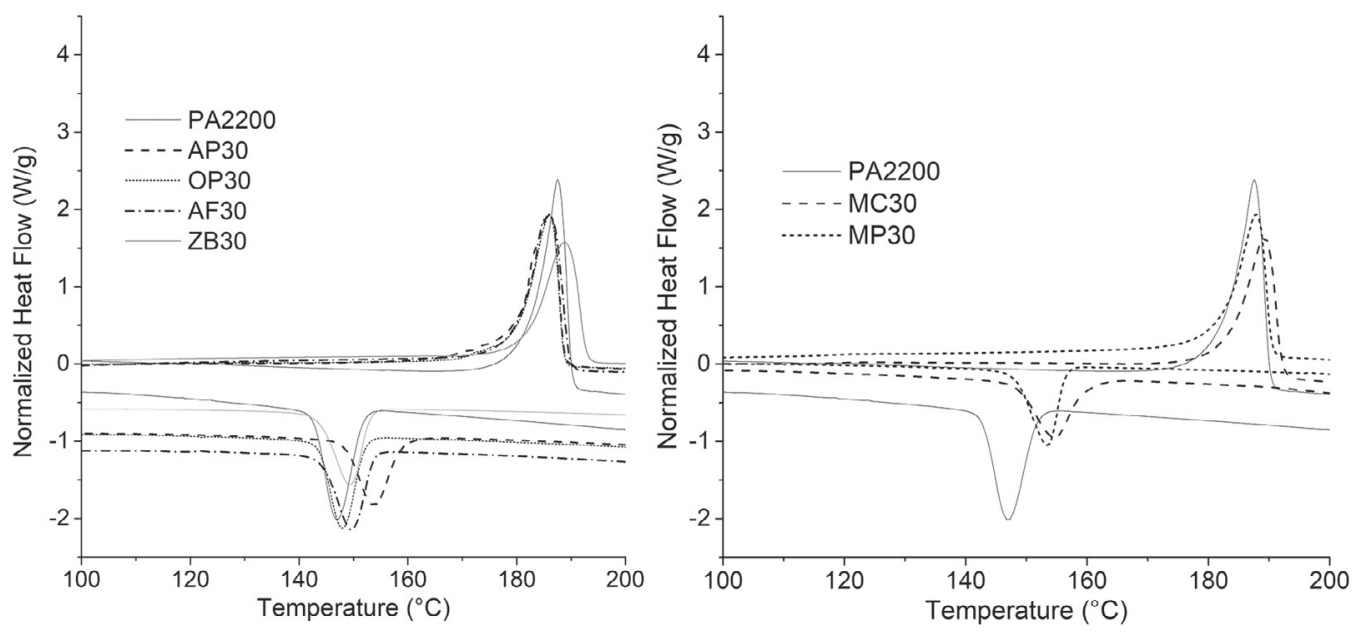

Fig. 2. DSC thermograms of formulations containing $30 \mathrm{wt} \%$ of flame retardants.

Table 2

Influence of flame retardants type on onset melt $\left(\mathrm{T}_{\mathrm{im}}\right)$ and crystallisation $\left(\mathrm{T}_{\mathrm{ic}}\right)$ temperatures.

\begin{tabular}{llll}
\hline Sample & $T_{i c}\left({ }^{\circ} \mathrm{C}\right)$ & $T_{i m}\left({ }^{\circ} \mathrm{C}\right)$ & $\Delta T\left({ }^{\circ} \mathrm{C}\right)$ \\
\hline PA & 153 & 179 & 26 \\
MC30 & 160 & 178 & 24 \\
MP30 & 157 & 178 & 23 \\
AP30 & 159 & 180 & 21 \\
AF30 & 153 & 180 & 27 \\
OP30 & 152 & 179 & 27 \\
ZB30 & 153 & 181 & 28 \\
AP15OP15 & 154 & 178 & 24 \\
AP15ZB15 & 158 & 182 & 24 \\
AP10OP10AB10 & 155 & 181 & 24 \\
AP10AF10ZB10 & 154 & 179 & 25 \\
AP10AF10ZB5KA5 & 154 & 179 & 25 \\
AP10AF10ZB5TA5 & 156 & 179 & 23 \\
\hline
\end{tabular}

The DSC thermograms of PA12 show a relatively sharp single endotherm with an onset crystallisation and melt temperatures of 153 and $179^{\circ} \mathrm{C}$ respectively. The single melt peak observed for PA12 is characteristic of a sample containing $100 \% \gamma$ crystal form [31]. Addition of flame retardants leads to a change of $\pm 1{ }^{\circ} \mathrm{C}$ indicating small changes in crystalline structure of PA12. Moreover, the addition of FRs leads to an increase in onset crystallisation temperatures which is more important for AP30, MP30 and MC30 formulations, probably due to a nucleating effect of these FRs.

Moreover, due to poor flowing parameters, it was not possible to process PA12 associated with MC or MP through SLS. Consequently, only four different flame retardants were incorporated in the SLS compositions, alone or in more complex compositions.
3.2. Selection of processing parameters and influence of additives on the processing window

The selection of processing parameters is of prime interest in order to achieve a good coalescence of particles leading to the minimization of the porosity of the samples. The laser power $P_{L S}(\mathrm{~J} / \mathrm{s})$ as well as the laser speed $V_{L S}(\mathrm{~mm} / \mathrm{s})$ and the distance between two scanning lines $d_{L S}(\mathrm{~mm})$, govern the energy density transmitted to the sample according to Eq. (2):

$E_{D}=\frac{P_{L S}}{V_{L S} \cdot d_{L S}}$

One of the difficulties concerning the SLS parts is related to its residual porosity which is in the 3-5\% range [32]. The increase of energy density could reduce the porosity and promote a relevant melting and coalescence of particles. Nevertheless, acting on $V_{L S}$ or $P_{L S}$ could lead to a thermal degradation of polymer or additive particles despite if in some cases a part of the energy is absorbed by the additives. For pure PA12, it was shown by Laumer et al. [33] that $85 \%$ of a $\mathrm{CO}_{2}$ laser irradiation is absorbed whereas $10 \%$ is reflected and $5 \%$ is transmitted.

Consequently, according to the nature of additives, different sets of processing parameters were applied with the aim to reduce the porosity. Moreover, it can be considered that various sets of parameters can be used to produce SLS objects in which the sintering process seems to be achieved. Table 3 presents the sintering parameters used for various compositions processed. Most of the compositions containing only FR additives could be processed using an energy density in the $0.7-1.8 \mathrm{~J} / \mathrm{cm}^{2}$ range.

Table 3

Sintering parameters used for each formulation.

\begin{tabular}{lllll}
\hline Sample & Chamber temperature $\left({ }^{\circ} \mathrm{C}\right)$ & Laser power $(\mathrm{W})$ & Laser scan speed $(\mathrm{mm} / \mathrm{s})$ & Energy density $\left(\mathrm{J} / \mathrm{cm}^{2}\right)$ \\
\hline PA & 142 & 4.2 & 2700 & 1.6 \\
AP30 & 142 & 4.2 & 2700 & 1.6 \\
OP30 & 4.9 & 2700 & 1.8 \\
AF30 & 142 & 4.9 & 2700 & 1.8 \\
ZB30 & 155 & 2.8 & 3600 & 0.8 \\
AP15OP15 & 142 & 2.8 & 2700 & 1.0 \\
AP15ZB15 & 153 & 2.8 & 3600 & 0.8 \\
AP10OP10ZB10 & 152 & 2.8 & 3600 & 0.8 \\
AP10AF10ZB10 & 150 & 2.8 & 3600 & 0.8 \\
AP10AF10ZB5KA5 & 155 & 2.8 & 3840 & 0.7 \\
AP10AF10ZB5TA5 & 155 & 2.8 & 3840 & 0.7 \\
\hline
\end{tabular}



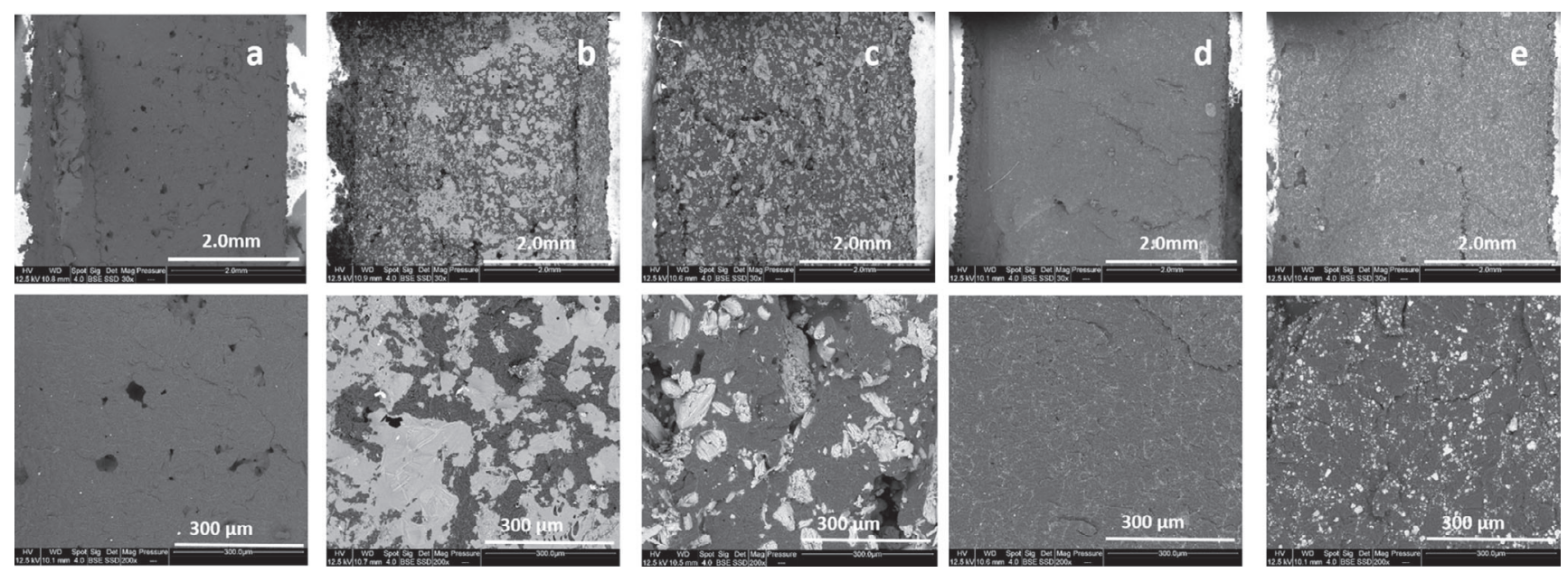

Fig. 3. SEM micrographs of cryofractured plates made by SLS: a) PA2200, b) AP30; c) OP30; d) AF30; e) ZB30.
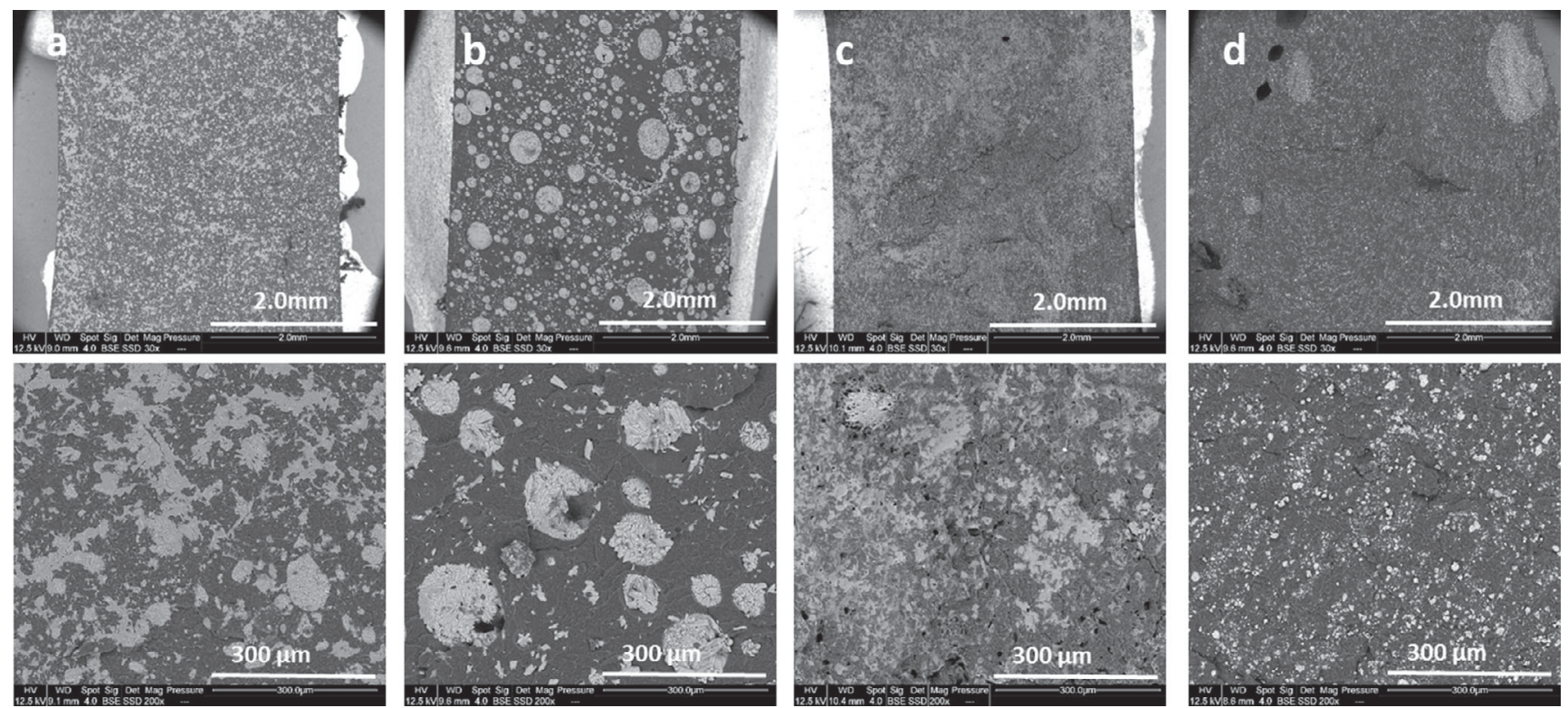

Fig. 4. SEM micrographs of cryofractured plates made by TC: a) AP30; b) OP30; c) AF30; d) ZB30.

\subsection{Morphology, porosity and thermal stability of the SLS materials}

The SEM pictures of cryofractured cross sections of PA12 with each FR made by SLS and TC are presented respectively in Figs. 3 and 4 . Regarding binary and ternary compositions made by SLS, pictures are presented in Fig. 5.

FR particles can be clearly distinguished for ZB and OP. In the case of phosphinate, the particles are aggregated. Only ZB30 appears homogeneous at macroscopic and microscopic scales, showing a good dispersion of zinc borate particles.

ZB acts as FR through the formation of a low-melting glassy structure and it has been used interestingly as FR synergist of melamine polyphosphate in PA6 [34] and PA6,6 [35], as well as synergist of aluminium phosphinate in PA6 [36]. It appears that the particles are not modified under the laser beam. Consequently, there is no protective structure formed prior to exposure of the corresponding sample to a radiant flux.

In the case of AP, the initial particles are not visible. Instead, plain areas that seem to correspond to a coalescence of softened APP particles are observed. This phenomenon appears to be more significant after SLS than TC.
In the case of Aflammit particles, the phenomenon is more pronounced since this additive appears to melt during SLS processing forming a homogeneous surface. TC corresponding samples seems less homogeneous but the particles are also not visible. For mixed compositions (Fig. 5), similar features can be noted for the compositions containing Aflammit.

Consequently, it can be expected that the porosity of SLS samples could be governed by the behaviour of their additives submitted to the energy supply.

Table 4 shows the porosities of SLS samples. It shows that the lower values are obtained for AF compositions, whereas the highest value is obtained by OP30. The corresponding picture showing some holes (Fig. 3b) may suggest that a partial thermal decomposition of zinc diethylphosphinate could occur due to laser irradiation. However, the examination of the TGA curves of the different FR additives shows that all of them are thermally stable up to $300^{\circ} \mathrm{C}$ (Fig. 6 and Table 5) and it appears that Firebrake ZB seems the more stable while Aflammit PCO900 is the less stable. Aluminium phosphinate has been the most studied among the phosphinates. It is known to act mainly in the gaseous phase as inhibitor, particularly in the case of polyamide 6,6 [35]. The influence of zinc 

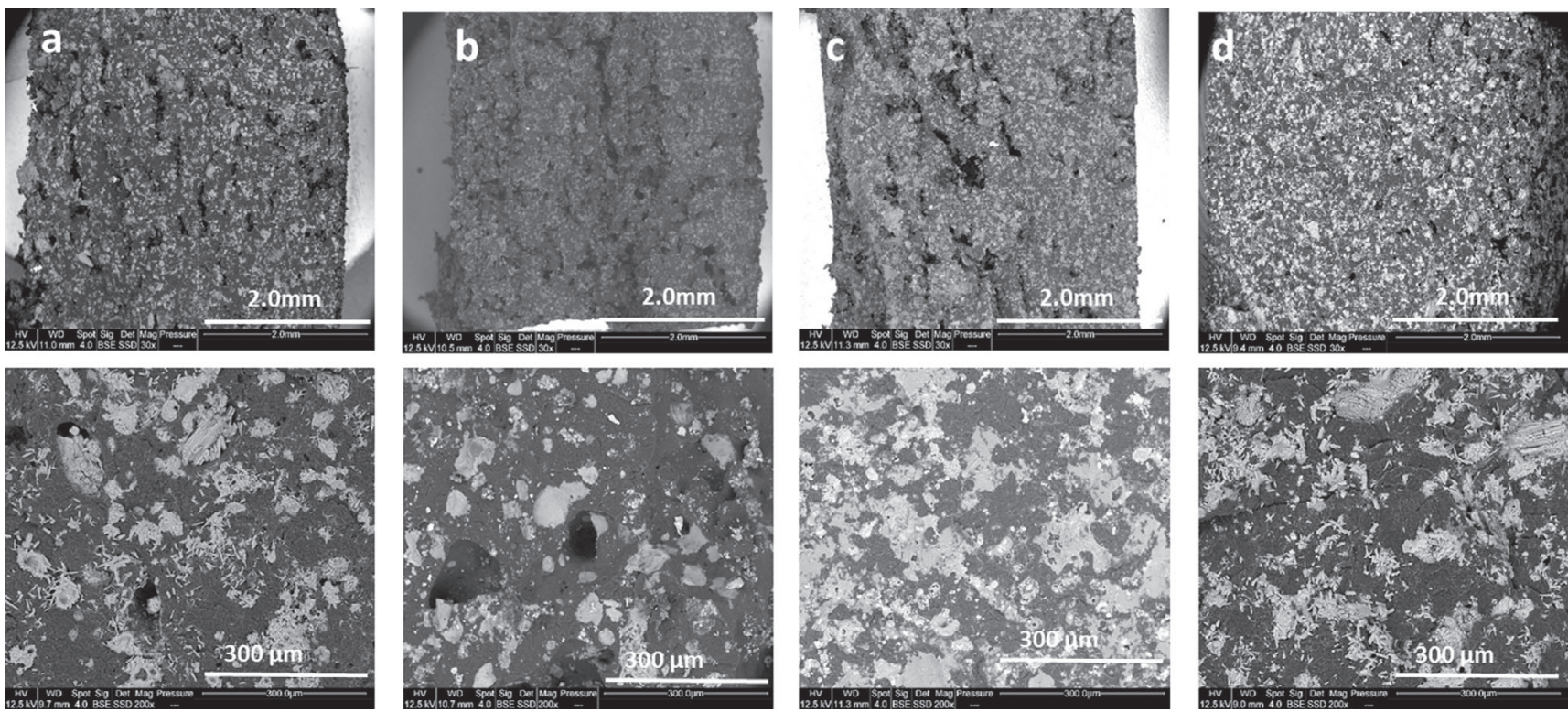

Fig. 5. SEM micrographs of cryofractured plates made by SLS: a) AP15OP15; b) AP15ZB15; c) AP10AF10ZB10; d) AP10OP10ZB10.

Table 4

Internal porosity values of SLS samples.

\begin{tabular}{ll}
\hline Sample & Porosity (\%) \\
\hline PA & 8 \\
AP30 & 7 \\
OP30 & 14 \\
AF30 & 5 \\
ZB30 & 8 \\
AP15OP15 & 7 \\
AP15ZB15 & 9 \\
AP10OP10ZB10 & 13 \\
AP10AF10ZB10 & 5 \\
AP10AF10ZB5KA5 & 14 \\
AP10AF10ZB5TA5 & 17 \\
\hline
\end{tabular}

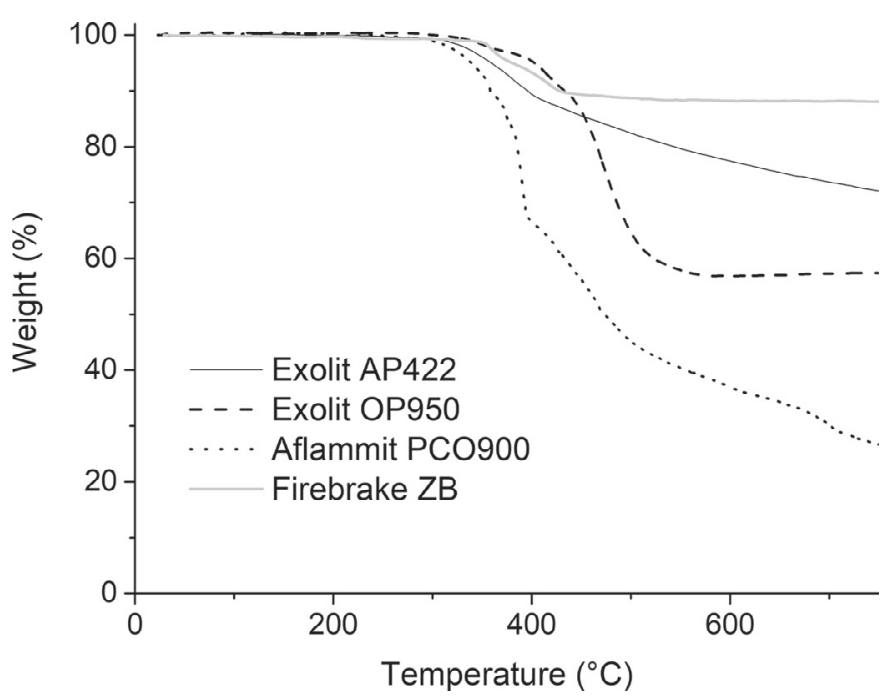

Fig. 6. TGA curves of flame retardants under nitrogen at $10^{\circ} \mathrm{C} / \mathrm{min}$.

diethylphosphinate in polyamide 11 has been investigated by Mandlekar et al. [36]. In nitrogen, zinc diethylphosphinate decomposes and generates a considerable amount of residue due to the formation of zinc pyrophosphates or phosphates in the condensed phase. In air, an intermediate step has been noted on TGA curves,
Table 5

TGA data of flame retardants.

\begin{tabular}{lllll}
\hline Sample & & & & Residue at \\
& $\mathrm{T}_{5 \%}\left({ }^{\circ} \mathrm{C}\right)$ & $\mathrm{T}_{20 \%}\left({ }^{\circ} \mathrm{C}\right)$ & $\mathrm{T}_{50 \%}\left({ }^{\circ} \mathrm{C}\right)$ & $750{ }^{\circ} \mathrm{C}(\%)$ \\
\hline Exolit AP422 & 359 & 544 & - & 69 \\
Exolit OP950 & 403 & 466 & - & 54 \\
Aflammit PCO900 & 339 & 386 & 472 & 26 \\
Firebrake ZB & 380 & - & - & 88 \\
\hline
\end{tabular}

Table 6

Characteristics of the degradation of TC samples.

\begin{tabular}{llllll}
\hline Sample & $\mathrm{T}_{5 \%}\left({ }^{\circ} \mathrm{C}\right)$ & $\mathrm{T}_{20 \%}\left({ }^{\circ} \mathrm{C}\right)$ & $\mathrm{T}_{50 \%}\left({ }^{\circ} \mathrm{C}\right)$ & $\begin{array}{l}\text { Experimental } \\
\text { residue at } \\
7500^{\circ} \mathrm{C}(\%)\end{array}$ & $\begin{array}{l}\text { Theoretical } \\
\text { residue at } \\
750^{\circ} \mathrm{C}(\%)\end{array}$ \\
\hline PA & 399 & 434 & 453 & 0 & 0 \\
AP30 & 349 & 372 & 385 & 20 & 21 \\
OP30 & 386 & 436 & 455 & 0 & 16 \\
AF30 & 363 & 400 & 424 & 16 & 8 \\
ZB30 & 415 & 444 & 463 & 26 & 26 \\
\hline
\end{tabular}

ascribed to the formation of phosphinates compounds and phosphinic acid such as in case of aluminium phosphinate. The thermal decomposition of APP is well known [37]. After a first step corresponding to the release of ammonia and water, crosslinked $\mathrm{P}-\mathrm{O}-\mathrm{P}$ are formed, leading to an important amount of residue in nitrogen $\left(80 \mathrm{wt} \%\right.$ at $\left.600^{\circ} \mathrm{C}\right)$. Concerning zinc borate, the mass loss corresponds only to the loss of water from the initial composition $\left(2 \mathrm{ZnO} \cdot 3 \mathrm{~B}_{2} \mathrm{O}_{3} \cdot 3.5 \mathrm{H}_{2} \mathrm{O}\right)$ [38].

Mass loss obtained by TGA for PA12 formulations made by SLS and TC are shown in Figs. 7 and 8. Complete results are given in Tables 6 and 7. Thermal degradation of PA2200 takes place in two steps and starts at about $406^{\circ} \mathrm{C}$ with a maximum mass loss rate at $460^{\circ} \mathrm{C}$. From studies dealing with the thermal degradation of polyamide 12 , thermal degradation products are mainly composed of $\mathrm{CO}, \mathrm{CO}_{2}$, hydrocarbons and dodecaprolactam $[23,37]$.

Considering the thermal stability of PA2200 and this of each FR component (Fig. 7), one can notice that the thermal stability of FR compositions does not follow exactly the same order as the FR additives indicating some interaction between FRs and PA12.

APP tends to particularly impair the stability of PA12 whatever the processing method. It can be ascribed to the release of water 

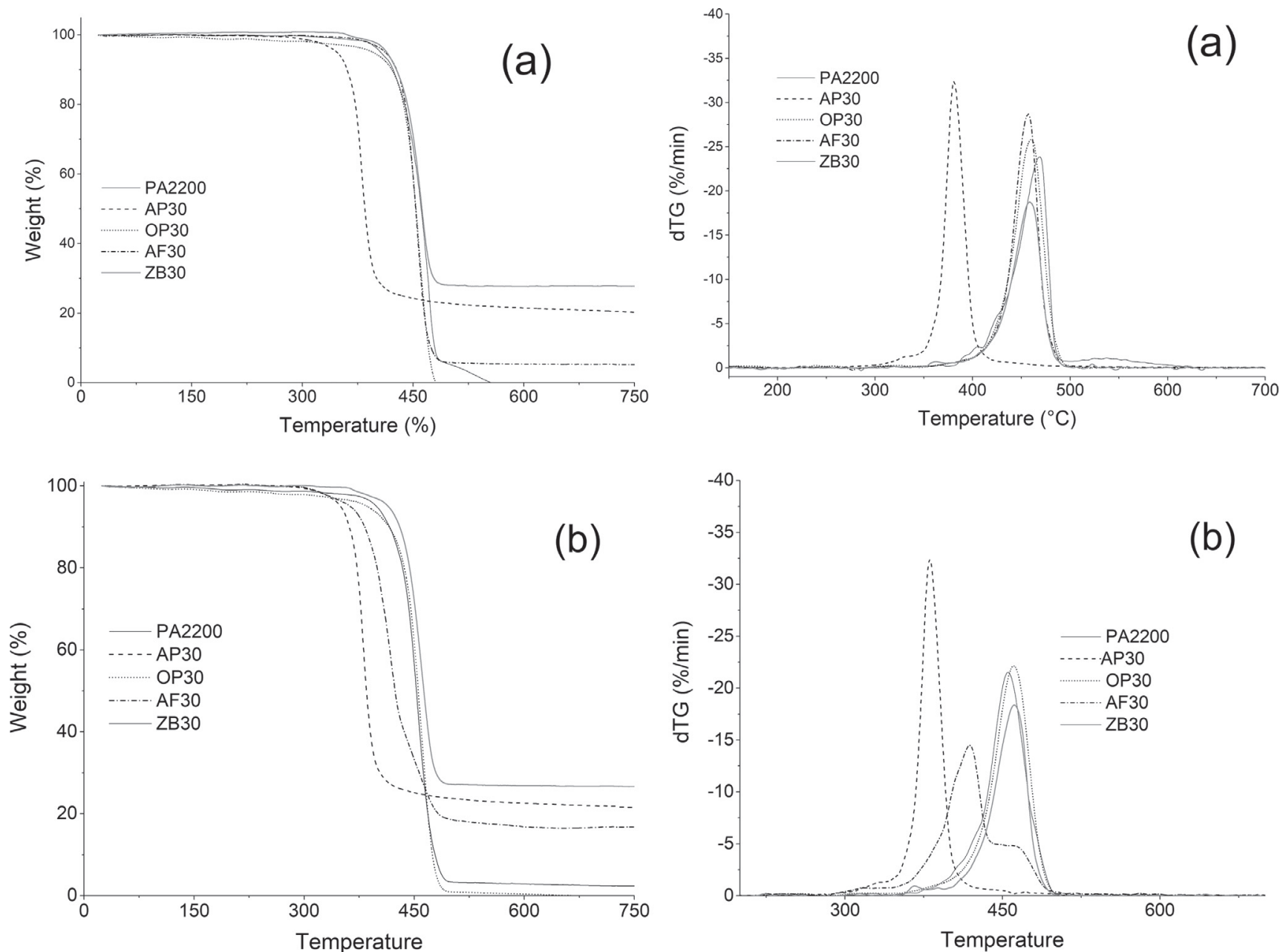

Fig. 7. TGA results under nitrogen at $10^{\circ} \mathrm{C} / \mathrm{min}$ of SLS (a) and TC (b) samples.
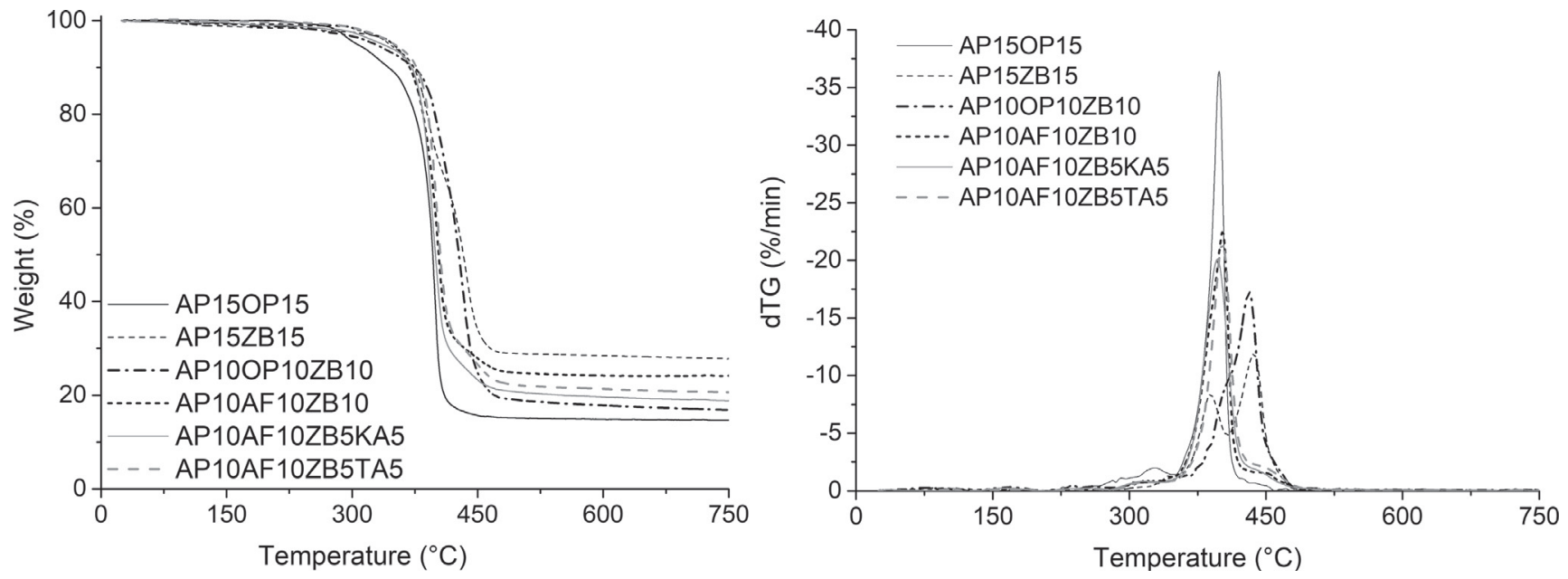

Fig. 8. TGA results under nitrogen at $10^{\circ} \mathrm{C} / \mathrm{min}$ of SLS binary and ternary formulations.

and ammonia at lower temperatures by APP [23] with a residue of $20 \%$ which corresponds to the theoretical residue for this formulation. Conversely, ZB and OP compositions exhibit the highest thermal stability.

A comparison between the experimental and the theoretical values of the residues based on those of the individual components is also presented for both processes in Tables 6 and 7. Theoretical values were computed by linear combination of PA12 and additives TGA curves:

$M_{t h}=\sum_{i} \% i \times M_{i}(T)$

Where $\% i$ is the initial weight-percentage of material $i$ in the composite, and $M_{i}(T)$ is the residual weight of material $i$ at 
Table 7

Characteristics of the degradation of SLS samples.

\begin{tabular}{llllll}
\hline Sample & & & & $\begin{array}{l}\text { Experimental } \\
\text { residue at } \\
750^{\circ} \mathrm{C}(\%)\end{array}$ & $\begin{array}{l}\text { Theoretical } \\
\text { residue at } \\
750^{\circ} \mathrm{C}(\%)\end{array}$ \\
\hline PA & $\mathrm{T}_{5 \%}\left({ }^{\circ} \mathrm{C}\right)$ & $\mathrm{T}_{20 \%}\left({ }^{\circ} \mathrm{C}\right)$ & $\mathrm{T}_{50 \%}\left({ }^{\circ} \mathrm{C}\right)$ & 0 & 0 \\
AP30 & 406 & 438 & 461 & 0 & 21 \\
OP30 & 347 & 372 & 385 & 20 & 16 \\
AF30 & 395 & 437 & 454 & 0 & 8 \\
ZB30 & 412 & 439 & 453 & 5 & 26 \\
AP15OP15 & 414 & 442 & 462 & 28 & 18 \\
AP15ZB15 & 305 & 375 & 396 & 15 & 24 \\
AP10OP10ZB10 & 344 & 389 & 433 & 28 & 18 \\
AP10AF10ZB10 & 327 & 399 & 428 & 17 & 21 \\
AP10AF10ZB5KA5 & 372 & 385 & 403 & 24 & 18.7 \\
AP10AF10ZB5TA5 & 350 & 398 & 423 & 32 & \\
\hline
\end{tabular}

Table 8

Cone calorimeter results of compositions containing each FR and comparison of SLS and TC samples.

\begin{tabular}{lllllll}
\hline Sample & $\begin{array}{l}\text { TTI } \\
(\mathrm{s})\end{array}$ & $\begin{array}{l}\text { pHRR } \\
\left(\mathrm{kW} / \mathrm{m}^{2}\right)\end{array}$ & $\begin{array}{l}\text { EHC } \\
(\mathrm{kJ} / \mathrm{g})\end{array}$ & $\begin{array}{l}\text { THR } \\
\left(\mathrm{MJ} / \mathrm{m}^{2}\right)\end{array}$ & $\begin{array}{l}\text { MARHE } \\
\left(\mathrm{kW} / \mathrm{m}^{2}\right)\end{array}$ & $\begin{array}{l}\text { Residue } \\
(\%)\end{array}$ \\
\hline PA SLS & 197 & 1580 & 34 & 151 & 422 & - \\
AP30 SLS & 83 & 632 & 31 & 135 & 321 & 19 \\
AP30 TC & 76 & 475 & 31 & 103 & 295 & 20 \\
OP30 SLS & 142 & 783 & 24 & 138 & 350 & 1.2 \\
OP30 TC & 213 & 617 & 27 & 105 & 223 & - \\
ZB30 SLS & 130 & 327 & 37 & 126 & 217 & 29 \\
ZB30 TC & 101 & 330 & 38 & 135 & 205 & 30 \\
AF30 SLS & 153 & 1224 & 37 & 145 & 376 & 2 \\
AF30 TC & 123 & 871 & 27 & 115 & 295 & 6 \\
\hline
\end{tabular}

temperature $T$. For AP and $\mathrm{ZB}$, whatever the process, there is no significant difference between the experimental and theoretical amount of residue. For OP, regardless the process, there is no experimental residue, conversely to what was expected, considering the residue formed by zinc diethylphosphinate. Hence, it can be suggested that the zinc phosphate formed from the decomposition of phosphinate could react with the polymer chains, leading to a complete decomposition of these phosphorylated structures at $500^{\circ} \mathrm{C}$.

The loss of stability for AF with a double degradation step is higher for TC than SLS samples, indicating that the additive could have been partially degraded during the processing stage. The results are very different regarding the processes and between experimental and theoretical residues. For TC samples, the highest value for the experimental residue can be explained by a strong charring action of the FR. Conversely, for SLS samples, the experimental residue is lower and this may be explained by a degradation of the molecule by the $\mathrm{CO}_{2}$ laser beam.

For the mixed compositions between FR components (Fig. 8), the lower degradation temperature observed corresponds to the joint presence of APP and zinc diethylphosphinate for which samples start to decompose from $250^{\circ} \mathrm{C}$. Table 7 indicates the onset temperatures, maximal degradation temperatures and final residues for the mixed compositions.

It can be noticed that for the two mixed compositions containing zinc diethylphosphinate (AP15OP15 and AP10OP10ZB10) the experimental residue is lower that the theoretical one. This could indicate that the laser irradiation could have thermally damaged zinc diethylphosphinate and have created an erosion phenomenon of the phosphinate particles. However, the energy density is lower for these mixed compositions compared to the compositions with individual FR. Hence, it can be considered that this low value of residue is only related to the interactions between zinc diethylphosphinate and PA12 as mentioned above.

For all compositions containing zinc borate, except AP100P10ZB10, the experimental residue is higher than the theoretical one, showing the positive effect of zinc borate on the formation of a stable residue. This is particularly the case of AP10AF10ZB10 for which the experimental residue is 33\% higher than the theoretical one.

Moreover, the presence of kaolin in addition to the ternary blend allows the final residue to be increased by $50 \%$. It is well known in literature that the addition of clays can lead to changes in thermal stability of polyamides due to a catalytic effect which can decrease the degradation temperature. The increase in final residue could be attributed to a barrier effect on mass transfer of decomposition products imparted by the submicronic lamellar particles.

\subsection{Fire tests on SLS and TC materials containing FR systems}

Cone calorimeter testing was performed on compositions containing individual FR components for SLS and TC samples, as well as on mixed compositions processed through SLS. Table 8 and Fig. 9 presents the mains results of fire tests performed on compositions made of individual FR by SLS and TC.

At first, all FR components used alone led to an improvement of fire performance, regardless of the process. pHRR, THR and MARHE are always reduced in comparison of the values for pristine PA12 processed through SLS.

The addition of FRs leads to a decrease of pHRR of about $60 \%$, $50 \%, 24 \%$ and $80 \%$ for AP30, OP30, AF30 and ZB30 SLS samples respectively. A significant decrease was also observed for TTI as a function of FR used. TC samples showed almost the same behaviour with an important decrease in terms of pHRR and TTI except for OP30 formulation. The addition of ammonium polyphosphate leads to a decrease in TTI due to lowering of the temperature of formation of volatile products and explain the observed behaviour. Aflammit and OP950 are less thermal stable than PA12 and start to degrade at lower temperatures than PA12 which could lead to a catalytic effect with the formation of small molecules at lower temperatures, leading to a decrease in TTI. Zinc borate starts 

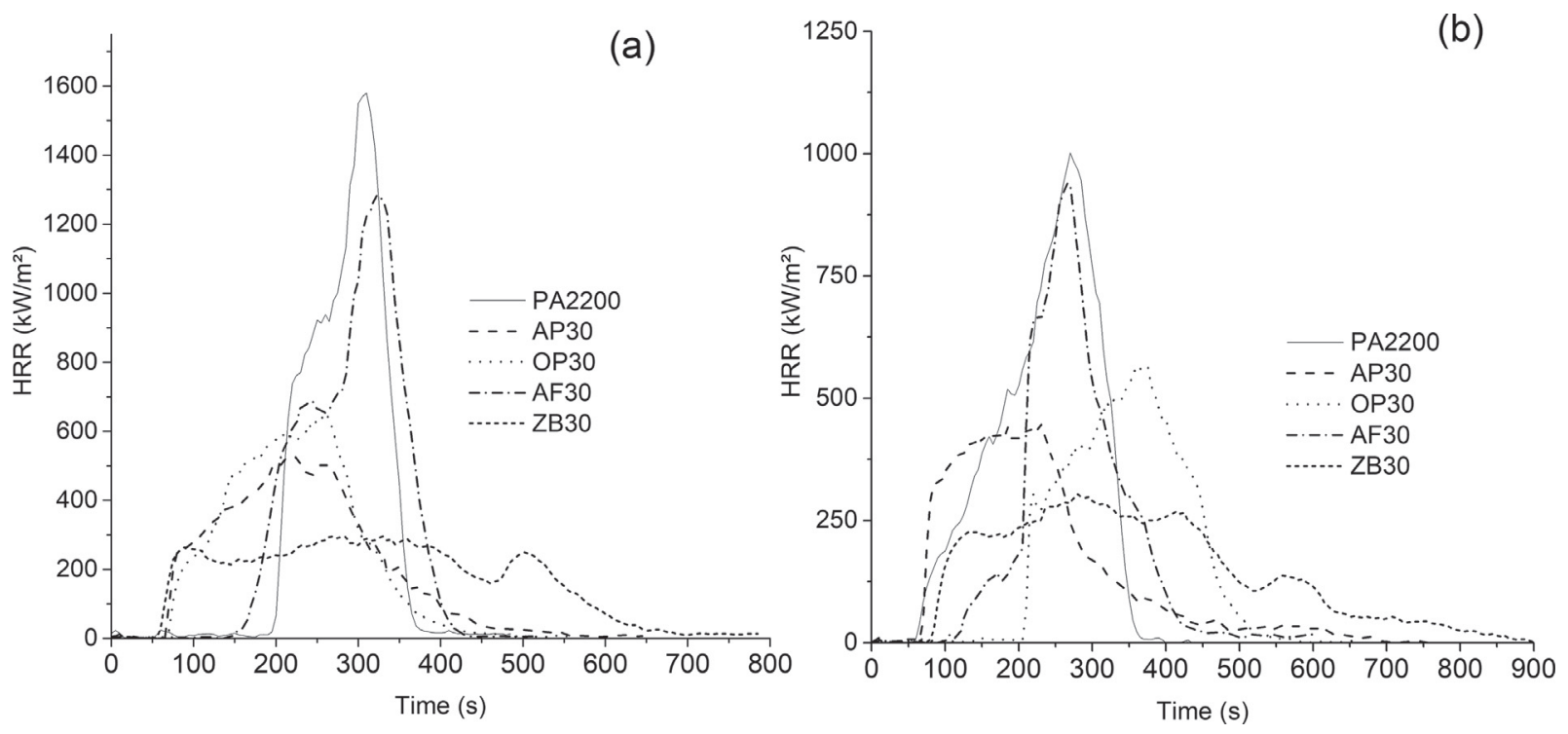

Fig. 9. Cone calorimeter results of (a) SLS and (b) TC compositions.

to degrade at about $400^{\circ} \mathrm{C}$ with the release of vapour water which could lead to a hydrolysis of polyamide chains and the formation of degradation products at lower temperatures.

On the whole, the results show that AP and particularly ZB seem to be the more performant. This can be ascribed to the ability of zinc borate to create a low-melting glassy structure able to protect the residual material against the heat flux and stabilize the char formed $[38,39]$. Zinc borate can release $13.5 \mathrm{wt} \%$ water with an endothermicity of $503 \mathrm{~J} / \mathrm{g}$ which is around one third of what aluminium or magnesium hydroxide release.

The comparison between SLS and TC shows that better results in terms of pHRR were obtained for the TC samples except for ZB30 formulation. This can be explained either by the initial porosity of this sample and its evolution during the thermal degradation at cone calorimeter or degradation of the FR additive during SLS process. It can be suggested that the formation of a molten glassy structure from zinc borate allows the porosity to be reduced in the first stages of exposure to the heat flux, entailing a similar behaviour between SLS and TC samples. It can be even noted that the TTI is higher for the SLS sample, meaning that the effect on hydrolysis of PA12 leading to the release of short polymer chains should be more important for the TC sample. Hence, for this FR it appears that the formation of the low-melting glassy structure during the fire test governs alone the fire behaviour.

The interest of $\mathrm{AF}$ and $\mathrm{OP}$ seems very limited. For AF, it is ascribed to degradation processes induced by the laser beam during SLS. From the TGA curve, it can be shown that a heat irradiation leading to a local value of temperature higher than $300^{\circ} \mathrm{C}$ is able to degrade significantly the FR molecule. From Table 4, it appears that the porosity of the phosphinate composition is among the highest (14\%). As in other additive manufacturing (AM) processes, such as fused filament fabrication (FFF), the presence of a significant porous fraction tends to enhance the diffusion of oxygen inside the material on one hand and the release of gaseous degradation products from the polymer on the other hand. Consequently, as shown by Regazzi et al. [40] for FDM FR compositions, the fire performance of AM samples will be lower than expected.

Concerning APP, the porosity fraction is also significant (7\%), and thereby can account for the difference of fire performance for SLS and TC samples. However, it seems not possible to correlate the porosity fraction with the loss of fire performance of all SLS samples in comparison with TC ones.
Moreover, the aspect of zinc borate particles after SLS processing seems very similar to the neat particles. This seems to indicate that their local temperature did not exceed $360^{\circ} \mathrm{C}$, which corresponds to the real starting point of the water release, according to Shen et al. [39]. To the best of our knowledge, no reference works have been published to date about the interest of this FR used alone in PA12. It can be explained by the propensity of zinc borate to release water which could lead to a detrimental effect of polymer hydrolysis occurring in processes involving molten polymers such as twin-screw extrusion or internal mixer. The particular interest of zinc borate used as FR through SLS processing is highlighted by the shape of the HRR curve which exhibits a plateau over a large range of the decomposition process. This kind of behaviour can be interpreted by the formation of thick charring structure able to protect the material and limit the mass transfer of degradation products to the gas phase and oxygen diffusion to the condensed phase [41]. A lower mass loss rate of degradation as well as a higher amount of residue were noted, higher than expected, considering the expected complete decomposition of PA12 and the water released by zinc borate. Consequently, a small part of the material remained unburnt and possibly charred under the protective layer brought by zinc borate.

In the case of AP, a significant residue was also formed, but in agreement with the mass loss expected for APP (from Fig. 6). There was no additional residue formed.

The flame properties of the five UL94 bars for each sample were measured at room temperature. Results are shown in Supporting Information. Neat PA12 is a flammable polymer and leads to a non-classed in UL94. The addition of OP950 and zinc borate did not lead to a significant difference compared to neat PA12, with the ignition of the cotton and no auto extinction. Zinc borate usually works by the formation of a surface layer which can protect the polymer from heat and decrease the mass transfer of volatile products. Yet, it was not effective to protect the sample in vertical burning tests. The addition of APP also led to the ignition of the cotton but the flame was extinguished after 10 seconds for each tested sample. The addition of Aflammit led to a V0 rating probably due to the action in gas phase of this flame retardant. Binary and ternary compositions did not lead to an improvement in UL94 rating probably due to the lower amount in Aflammit and APP flame retardants. 
Table 9

Cone calorimeter parameters for mixed compositions.

\begin{tabular}{lllllll}
\hline Sample & $\begin{array}{l}\text { TTI } \\
(\mathrm{s})\end{array}$ & $\begin{array}{l}\text { pHRR } \\
\left(\mathrm{kW} / \mathrm{m}^{2}\right)\end{array}$ & $\begin{array}{l}\text { EHC } \\
(\mathrm{kJ} / \mathrm{g})\end{array}$ & $\begin{array}{l}\text { THR } \\
\left(\mathrm{MJ} / \mathrm{m}^{2}\right)\end{array}$ & $\begin{array}{l}\text { MARHE } \\
\left(\mathrm{kW} / \mathrm{m}^{2}\right)\end{array}$ & $\begin{array}{l}\text { Residue } \\
(\%)\end{array}$ \\
\hline PA & 197 & 1580 & 34 & 151 & 422 & - \\
AP15OP15 & 85 & 663 & 30 & 128 & 342 & 25 \\
AP15ZB15 & 51 & 407 & 35 & 135 & 266 & 35 \\
AP10OP10ZB10 & 81 & 431 & 33 & 145 & 235 & 22 \\
AP10AF10ZB10 & 65 & 420 & 29 & 112 & 211 & 24 \\
AP10AF10ZB5KA5 & 58 & 280 & 30 & 128 & 160 & 24 \\
AP10AF10ZB5TA5 & 89 & 553 & 29 & 122 & 287 & 21 \\
\hline
\end{tabular}

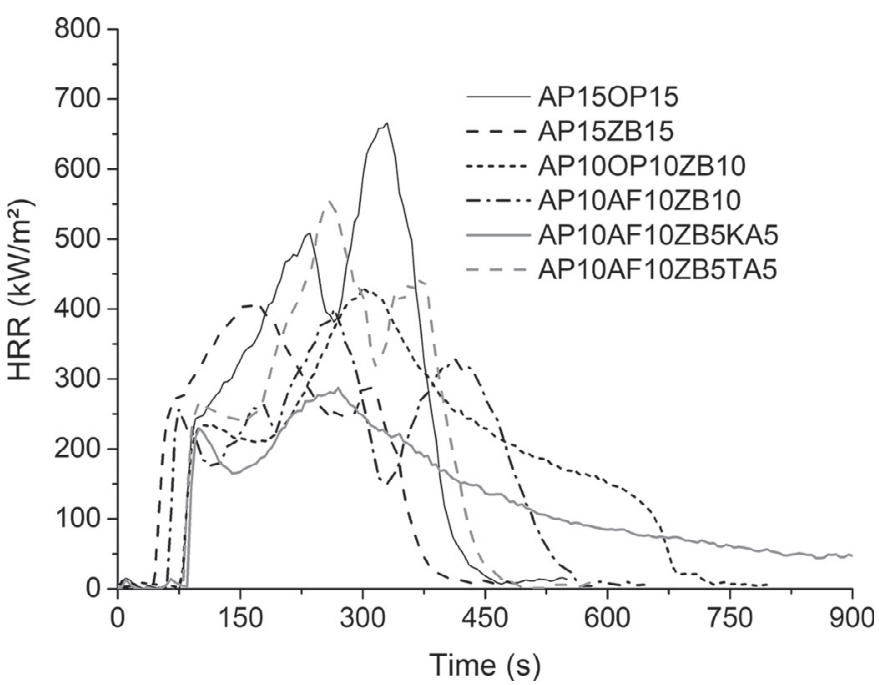

Fig. 10. Cone calorimeter results of mixed compositions.

\subsection{Compositions with combinations of FRs and ultrafine particles}

Various compositions were processed from a physical mixing of PA12 powders and two or even three kinds of FRs. As mentioned previously, the aim was to investigate possible synergistic effects resulting from different modes of action, in particular those taking place in the condensed phase (through intumescence or formation of a low-melting glassy structure) and in the gaseous phase (through release of phosphorous free radicals).

Table 9 and Fig. 10 present the results concerning the different fire parameters for mixed FR compositions. For all these compositions, the time to ignition is notably reduced in comparison with pristine PA2200. This attributed to the presence in all compositions of APP which reacts with PA12, by promoting release of combustible species but also char formation, leading to a protective action of the residual material. For compositions containing both APP and zinc borate, pHRR and MARHE are significantly reduced. Moreover, for all compositions, the final residue is higher than the theoretical value. The incorporation of ultrafine fillers is only interesting in the case of kaolinite, possibly due to a better dispersion in PA12. Comparing AP10AF10ZB10 and AP10AF10ZB5KA5, the partial substitution of zinc borate by kaolinite appears advantageous for pHRR and MARHE but not TTI. This can be ascribed to a barrier effect of ultrafine kaolinite particles, already highlighted in a previous work [21] and to a possible reinforcement of the low-melting glassy structure resulting from the softening of zinc borate particles by the kaolinite particles.

\subsection{Study of cone calorimeter residues}

Digital photographs of residues are presented Fig. 11. It appears that all compositions containing zinc borate are strongly charred, expanded and correspond to intumescent behaviours. AP10AF10ZB5KA5 which presents the lower pHRR value exhibits the highest expansion.

Characterizations of the composition and chemical structure of residues using energy-dispersive X-ray spectroscopy and X-rays diffraction were carried out in order to complete the investigations about the fire-retardant mechanisms imparted by the different FR used.

X-ray diffraction spectra of AP30 and AF30 residues shows the formation of an amorphous structure (Supporting Information. The addition of $\mathrm{ZB}$ leads to the formation of two crystalline phases $\left(\mathrm{Zn}_{4} \mathrm{~B}_{6} \mathrm{O}_{13}\right.$ and $\left.\mathrm{ZnB}_{4} \mathrm{O}_{7}\right)$. This is in agreement with Samyn et al. [42] who identified both compounds, but only at $800^{\circ} \mathrm{C}$, whereas the first one was not identified at $580^{\circ} \mathrm{C}$. At lower temperature, only amorphous structures were highlighted. However, in the above-mentioned work, residues were obtained from TGA experiments for neat zinc borate, and with a different temperature profile than in cone calorimeter. It should be remembered that OP does not lead to any residue.

Mixtures of flame retardants lead to specific fire reactions in relation to the composition and structure of the residues formed. For AP15ZB15, the chemical structures formed in the residues are completely different from those observed for both AP30 and ZB30 (Supporting Information). A crystalline phase is observed which corresponds to the formation of zinc phosphate and boron orthophosphate species [42]. APP starts to decompose at about $260^{\circ} \mathrm{C}$ by the release of ammonia, water and polyphosphoric acid. At $290^{\circ} \mathrm{C}$ the degradation of zinc borate starts with the release of water and the formation of an amorphous structure. From $300^{\circ} \mathrm{C}$, a reaction between APP and zinc borate can take place with the formation of $\mathrm{BPO}_{4}$ species. At higher temperatures, the formation of zinc orthophosphate was noticed. It is considered that the creation of zinc phosphate and borophosphate species contributes to the stabilization of phosphorous species [43].

The addition of Aflammit (AP10AF10ZB10) or zinc diethylphosphinate (AP10OP10ZB10) does not lead to significant changes for the XRD spectra and fire parameters, compared to the AP15ZB15 formulation with the formation of zinc phosphate and borophosphate crystalline phases.

However, the addition of kaolin (AP10AF10ZB5KA5) or talc (AP10AF10ZB5TA5) leads to a destabilization with the formation of only boron oxide, boron phosphate and an amorphous phase (shoulder between 15 and $30^{\circ} 2 \theta^{\circ}$, which is supposed to be mainly composed of zinc species, able to form a glassy surface layer, limiting the oxygen penetration into the bulk material as well as heat and mass transfer.

Energy-dispersive X-ray spectroscopy of residues was performed in order to correlate the fire performance to the phosphorus content remaining in the char. Table 10 indicates the ratio between the mass of phosphorus in the char $M_{P r}$ and the initial mass of phosphorus present before testing $M_{P i}$ according to Eq. (3):

$P(\%)=\frac{M_{P r}}{M_{P i}} \times 100$ 

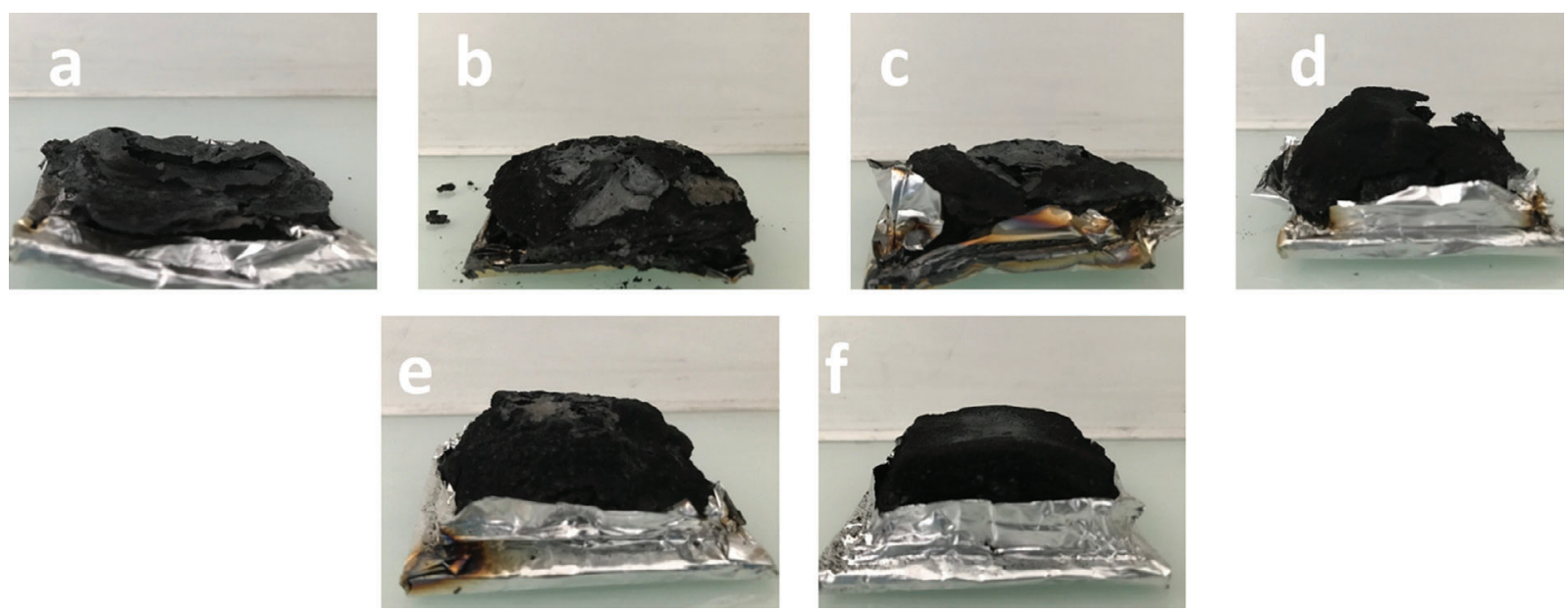

Fig. 11. Cone calorimeter residues of SLS samples: a) ZB30; bf) AP15ZB15; c) AP10OP10ZB10; d) AP10AF10ZB10; e) AP10AF10ZB5KA5; f) AP10AF10ZB5TA5.

Table 10

Phosphorus content in SLS samples before and after cone calorimeter tests.

\begin{tabular}{llllll}
\hline Sample & $P i(\%)$ & $M_{P i}(\mathrm{~g})$ & $\operatorname{Pr}(\%)$ & $M_{P r}(\mathrm{~g})$ & $P(\%)$ \\
\hline AP30 & 9.5 & 1.87 & 35.0 & 1.32 & 70.6 \\
AF30 & 7.0 & 1.54 & 24.2 & 0.11 & 7.1 \\
ZB30 & 0 & 0 & 0 & 0 & 0 \\
AP15OP15 & 7.7 & 1.65 & 27.8 & 1.49 & 90.3 \\
AP15ZB15 & 4.7 & 1.07 & 19.0 & 1.03 & 96.3 \\
AP10OP10ZB10 & 5.2 & 1.17 & 24.2 & 1.15 & 98.3 \\
AP10AF10ZB10 & 5.5 & 1.15 & 24.5 & 1.13 & 98.3 \\
AP10AF10ZB5KA5 & 5.5 & 1.17 & 25.0 & 1.12 & 95.7 \\
AP10AF10ZB5TA5 & 5.5 & 1.14 & 25.3 & 1.11 & 97.4 \\
\hline
\end{tabular}

For AF30, almost $93 \mathrm{wt} \%$ of the phosphorus is released in gas phase, indicating that the mode of action would be flame inhibition even if the fire performance is limited.

In the case of AP30, around $30 \mathrm{wt} \%$ of phosphorus is released in gas phase. In comparison, only $10 \mathrm{wt} \%$ of phosphorus is released for AP15OP15, indicating that the combination of zinc diethylphosphinate with ammonium polyphosphate allows the amount of phosphorus in the residue to be significantly increased. However, it can be noted that the increase of both the amount of residue and the phosphorus content does not lead to an improvement of the fire reaction.

For binary and ternary formulations, the use of zinc borate leads to a strong increase of the phosphorus content in the residues in comparison with APP alone. It can be noticed that almost all the phosphorus content of Aflammit can be retained in the residue thanks to the presence of zinc borates which promotes borophosphate and zinc borate formation. For the three binary and ternary compositions with $\mathrm{AP}$ and $\mathrm{ZB}$, such very high levels of phosphorus retention correspond to pHRR values between 400 and $430 \mathrm{~kW} / \mathrm{m}^{2}$ and MAHRE values between 210 and $270 \mathrm{~kW} / \mathrm{m}^{2}$.

The use of kaolin and talc (AP10AF10ZB5KA5 and AP10AF10ZB5TA5) also enables the retention of phosphorus, but slightly lesser than AP10OP10ZB10. Consequently, it appears that the amorphous structure promoted by the presence of kaolinite is also able to retain a significant amount of phosphorus in the residue.

\section{Conclusions}

Flame retarded compositions of PA12 were processed via the SLS additive manufacturing technology. At first, a comparison of the fire performance of each individual flame retardant in PA12 was carried out. In addition, these results were compared to the corresponding samples processed by thermocompression. Then, the performances of several combinations of flame retardants in PA12 were evaluated.

It has been shown that the possibility to use flame retardant additives in SLS depends on the ability to preserve a sufficient temperature range of processing. For various compositions, different processing parameters can be used in order to keep the same energy density. However, various compositions could not be processed due to a poor flowing behaviour of blended powders.

It appeared that SLS allows different flame retardant additives or their combinations to be used, when compared to moulding techniques. Hence, hydrolysis processes can be avoided. Nevertheless, the ability of additives to withstand the local rise of temperature caused by the laser beam is essential (i.e. the absorptivity at the laser wavelength). It has been noticed in particular that Aflammit was partially damaged during the SLS process.

For the compositions in which only one flame retardant was used, zinc borate leads to the best fire performance. SLS and thermo-compression samples exhibited similar results. This was caused by a relatively low porosity of the SLS samples and the ability of zinc borate to form low-melting amorphous structures able to crystallize at higher temperature, leading to a compact and protective residual structure. Moreover, the presence of zinc borate in mixed compositions is able, through the formation of zinc phosphates and borophosphate, to retain nearly all the phosphorus present in the composition, even with Aflammit, leading to a good fire performance in comparison with other compositions evaluated in this work.

The interest of the substitution of a fraction of zinc borate in mixed compositions by kaolinite has been highlighted. At first sight, it can be ascribed to a barrier effect, but it has to be noted that the presence of kaolinite entails the formation of different structures from those identified using X-ray diffraction with only zinc borate. However, the performance imparted by kaolinite could be dependent on its state of dispersion. It can be expected that dispersion of ultrafine lamellar fillers used as a barrier effect promoter could be improved by coating them on the PA12 powders. Further work is ongoing about this procedure.

\section{Declaration of Competing Interest}

The authors declare that they have no known competing financial interests or personal relationships that could have appeared to influence the work reported in this paper. 


\section{CRediT authorship contribution statement}

Marcos Batistella: Conceptualization, Methodology, Formal analysis, Writing - original draft, Investigation. Arnaud Regazzi: Supervision, Writing - review \& editing. Monica Francesca Pucci: Visualization, Investigation, Supervision, Writing - review \& editing. José-Marie Lopez-Cuesta: Supervision, Writing - original draft. Ouassila Kadri: Validation, Writing - review \& editing. David Bordeaux: Validation, Writing - review \& editing. Florence Ayme: Validation, Writing - review \& editing.

\section{Acknowledgements}

Authors would like to thank the European Union (FEDER funding for the Occitanie region), and the Occitanie region for funding the POLIFRIL project that led to this study.

\section{Supplementary materials}

Supplementary material associated with this article can be found, in the online version, at doi:10.1016/j.polymdegradstab. 2020.109318

\section{References}

[1] A.D. Valino, J.R.C. Dizon, A.H. Espera, Q. Chen, J. Messman, R.C. Advincula, Advances in 3D printing of thermoplastic polymer composites and nanocomposites, Prog. Polym. Sci. 98 (2019) 101162, doi:10.1016/j.progpolymsci.2019 101162.

[2] X. Wang, M. Jiang, Z. Zhou, J. Gou, D. Hui, 3D printing of polymer matrix composites: a review and prospective, Compos. Part B Eng. 110 (2017) 442-458, doi:10.1016/j.compositesb.2016.11.034.

[3] T.T. Wohlers, 3D printing of polymer matrix composites: a review and prospective, Fort Collins (2016)

[4] M. Schmid, Selektives Lasersintern (SLS) mit Kunststoffen Technologie, Prozesse und Werkstoffe (2015)

[5] D. Drummer, S. Greiner, M. Zhao, K. Wudy, A novel approach for understanding laser sintering of polymers, Addit. Manuf. 27 (2019) 379-388, doi:10.1016 j.addma.2019.03.012.

[6] C.A. Chatham, T.E. Long, C.B. Williams, A review of the process physics and material screening methods for polymer powder bed fusion additive manufacturing, Prog. Polym. Sci. 93 (2019) 68-95, doi:10.1016/j.progpolymsci.2019.03.003.

[7] J.P. Kruth, X. Wang, T. Laoui, L. Froyen, Lasers and materials in selective lase sintering, Assem. Autom. 23 (2003) 357-371, doi:10.1108/01445150310698652.

[8] J. Schmidt, M. Sachs, S. Fanselow, M. Zhao, S. Romeis, D. Drummer, K.E. Wirth, W. Peukert, Optimized polybutylene terephthalate powders for selective laser beam melting, Chem. Eng. Sci. 156 (2016) 1-10, doi:10.1016/j.ces.2016.09.009.

[9] M. Schmid, K. Wegener, Additive Manufacturing: polymers applicable for lase sintering (LS), Procedia Eng. 149 (2016) 457-464, doi:10.1016/j.proeng.2016.06. 692.

[10] A.J. Cano, A. Salazar, J. Rodríguez, Effect of temperature on the fracture behavior of polyamide 12 and glass-filled polyamide 12 processed by selective laser sintering, Eng. Fract. Mech. 203 (2018) 66-80, doi:10.1016/j.engfracmech.2018. 07.035 .

[11] J. Bai, J. Song, J. Wei, Tribological and mechanical properties of MoS 2 enhanced polyamide 12 for selective laser sintering, J. Mater. Process. Technol. 264 (2019) 382-388, doi:10.1016/j.jmatprotec.2018.09.026.

[12] G.V. Salmoria, R.A. Paggi, A. Lago, V.E. Beal, Microstructural and mechanical characterization of PA12/MWCNTs nanocomposite manufactured by selective laser sintering, Polym. Test. 30 (2011) 611-615, doi:10.1016/j.polymertesting. 2011.04.007.

[13] C. Yan, L. Hao, L. Xu, Y. Shi, Preparation, characterisation and processing of carbon fibre/polyamide-12 composites for selective laser sintering, Compos. Sci. Technol. 71 (2011) 1834-1841, doi:10.1016/j.compscitech.2011.08.013.

[14] W. Jing, C. Hui, W. Qiong, L. Hongbo, L. Zhanjun, Surface modification of carbon fibers and the selective laser sintering of modified carbon fiber/nylon 12 composite powder, Mater. Des. 116 (2017) 253-260, doi:10.1016/j.matdes.2016. 12.037.

[15] R.D. Goodridge, M.L. Shofner, R.J.M. Hague, M. McClelland, M.R. Schlea, R.B. Johnson, C.J. Tuck, Processing of a polyamide-12/carbon nanofibre composite by laser sintering, Polym. Test. 30 (2011) 94-100, doi:10.1016/j. polymertesting.2010.10.011.

[16] H. Chung, S. Das, Processing and properties of glass bead particulate-filled functionally graded Nylon-11 composites produced by selective laser sintering, Mater. Sci. Eng. A. 437 (2006) 226-234, doi:10.1016/j.msea.2006.07.112.
[17] K. Shahzad, J. Deckers, S. Boury, B. Neirinck, J.P. Kruth, J. Vleugels, Preparation and indirect selective laser sintering of alumina/PA microspheres, Ceram. Int 38 (2012) 1241-1247, doi:10.1016/j.ceramint.2011.08.055.

[18] T.J. Gill, K.K.B. Hon, Experimental investigation into the selective laser sintering of silicon carbide polyamide composites, Proc. Inst. Mech. Eng. Part B J. Eng. Manuf. 218 (2004) 1249-1256, doi:10.1243/0954405042323487.

[19] S.R. Athreya, K. Kalaitzidou, S. Das, Processing and characterization of a carbon black-filled electrically conductive nylon- 12 nanocomposite produced by selective laser sintering, Mater. Sci. Eng. A. 527 (2010) 2637-2642, doi:10.1016/j. msea.2009.12.028.

[20] A. Mazzoli, G. Moriconi, M.G. Pauri, Characterization of an aluminum-filled polyamide powder for applications in selective laser sintering, Mater. Des. 28 (2007) 993-1000, doi:10.1016/j.matdes.2005.11.021.

[21] M.A. Batistella, R. Sonnier, B. Otazaghine, C.O. Petter, J.-M. Lopez-Cuesta, Interactions between kaolinite and phosphinate-based flame retardant in Polyamide 6, Appl. Clay Sci. 157 (2018), doi:10.1016/j.clay.2018.02.021.

[22] W. He, H. Zhu, Y. Xiang, L. Long, S. Qin, J. Yu, Enhancement of flame retardancy and mechanical properties of polyamide 6 by incorporating an aluminum salt of diisobutylphosphinic combined with organoclay, Polym. Degrad. Stab. 144 (2017) 442-453, doi:10.1016/j.polymdegradstab.2017.09.003.

[23] S.V.V. Levchik, L. Costa, G. Camino, Effect of the fire-retardant, ammonium polyphosphate, on the thermal decomposition of aliphatic polyamides: part II-polyamide 6, Polym. Degrad. Stab. 36 (1992) 229-237, doi:10.1016 0141-3910(92)90060-I.

[24] Y. Liu, Z. Feng, Q. Wang, The investigation of intumescent flame-retardant polypropylene using a new macromolecular charring agent polyamide 11 , Polym. Compos. 30 (2009) 221-225, doi:10.1002/pc.20555.

[25] S.C. Lao, C. Wu, T.J. Moon, J.H. Koo, A. Morgan, L. Pilato, G. Wissler, Flame-retardant polyamide 11 and 12 nanocomposites: thermal and flammability properties, J. Compos. Mater. 43 (2009) 1803-1818, doi:10.1177| 0021998309338413.

[26] S.C. Lao, W. Yong, K. Nguyen, T.J. Moon, J.H. Koo, L. Pilato, G. Wissler, Flameretardant polyamide 11 and 12 nanocomposites: processing, morphology, and mechanical properties, J. Compos. Mater. 44 (2010) 2933-2951, doi:10.1177| 0021998310369580

[27] S. Gentiluomo, A.D. Veca, M. Monti, M. Zaccone, M. Zanetti, Fire behavior of polyamide 12 nanocomposites containing POSS and CNT, Polym. Degrad. Stab. 134 (2016) 151-156, doi:10.1016/j.polymdegradstab.2016.10.005.

[28] L. Clerc, L. Ferry, E. Leroy, J.-M.M. Lopez-Cuesta, Influence of talc physical properties on the fire retarding behaviour of (ethylene-vinyl acetate copolymer/magnesium hydroxide/talc) composites, Polym. Degrad. Stab. 88 (2005) 504-511, doi:10.1016/j.polymdegradstab.2004.12.010.

[29] M. Batistella, B. Otazaghine, R. Sonnier, C. Petter, J.-M. Lopez-Cuesta, Fire retardancy of polypropylene/kaolinite composites, Polym. Degrad. Stab. 129 (2016) 260-267, doi:10.1016/j.polymdegradstab.2016.05.003.

[30] L. Ferry, R. Sonnier, J.-M. Lopez-Cuesta, S. Petigny, C. Bert, Thermal degradation and flammability of polyamide 11 filled with nanoboehmite, J. Therm. Anal. Calorim. 129 (2017) 1029-1037, doi:10.1007/s10973-017-6244-1.

[31] T. Ishikawa, S. Nagai, N. Kasai, Thermal behavior of $\alpha$ nylon-12, J. Polym. Sci. Polym. Phys. Ed. 18 (1980) 1413-1419, doi:10.1002/pol.1980.180180619.

[32] G. Flodberg, H. Pettersson, L. Yang, Pore analysis and mechanical performance of selective laser sintered objects, Addit. Manuf. 24 (2018) 307-315, doi:10. 1016/j.addma.2018.10.001.

[33] T. Laumer, T. Stichel, K. Nagulin, M. Schmidt, Optical analysis of polymer powder materials for Selective Laser Sintering, Polym. Test. 56 (2016) 207-213, doi:10.1016/j.polymertesting.2016.10.010.

[34] Q. Tai, R.K.K. Yuen, W. Yang, Z. Qiao, L. Song, Y. Hu, Iron-montmorillonite and zinc borate as synergistic agents in flame-retardant glass fiber reinforced polyamide 6 composites in combination with melamine polyphosphate, Compos. Part A Appl. Sci. Manuf. 43 (2012) 415-422, doi:10.1016/j.compositesa. 2011.10.012.

[35] U. Braun, B. Schartel, M.A. Fichera, C. Jäger, Flame retardancy mechanisms of aluminium phosphinate in combination with melamine polyphosphate and zinc borate in glass-fibre reinforced polyamide 6,6, Polym. Degrad. Stab. 92 (2007) 1528-1545, doi:10.1016/j.polymdegradstab.2007.05.007.

[36] N. Mandlekar, G. Malucelli, A. Cayla, F. Rault, S. Giraud, F. Salaün, J. Guan, Fire retardant action of zinc phosphinate and polyamide 11 blend containing lignin as a carbon source, Polym. Degrad. Stab. 153 (2018) 63-74, doi:10.1016 | j.polymdegradstab.2018.04.019.

[37] G. Camino, L. Costa, L. Trossarelli, Study of the mechanism of intumescence in fire retardant polymers: part V-mechanism of formation of gaseous products in the thermal degradation of ammonium polyphosphate, Polym. Degrad. Stab. 12 (1985) 203-211, doi:10.1016/0141-3910(85)90089-8.

[38] L.A. Savas, M. Dogan, Flame retardant effect of zinc borate in polyamide 6 containing aluminum hypophosphite, Polym. Degrad. Stab. 165 (2019) 101-109, doi:10.1016/j.polymdegradstab.2019.05.005.

[39] K.K. Shen, S. Kochesfahani, F. Jouffret, Zinc borates as multifunctional polyme additives, Polym. Adv. Technol. 19 (2008) 469-474, doi:10.1002/pat.1119.

[40] A. Regazzi, M.F. Pucci, L. Dumazert, B. Gallard, S. Buonomo, R. Ravel, J.M. Lopez-Cuesta, Controlling the distribution of fire retardants in poly(lactic acid) by fused filament fabrication in order to improve its fire behaviour, Polym. Degrad. Stab. 163 (2019) 143-150, doi:10.1016/j.polymdegradstab.2019. 03.008 . 
[41] B. Schartel, T.R. Hull, Development of fire-retarded materials-interpretation of cone calorimeter data, Fire Mater. 31 (2007) 327-354, doi:10.1002/fam.949.

42] F. Samyn, S. Bourbigot, S. Duquesne, R. Delobel, Effect of zinc borate on the thermal degradation of ammonium polyphosphate, Thermochim. Acta. 456 (2007) 134-144, doi:10.1016/j.tca.2007.02.006.
[43] P. Khalili, X. Liu, K.Y. Tshai, C. Rudd, X. Yi, I. Kong, Development of fire retardancy of natural fiber composite encouraged by a synergy between zinc borate and ammonium polyphosphate, Compos. Part B Eng. 159 (2019) 165-172, doi:10.1016/j.compositesb.2018.09.036. 